\title{
Media Video Informasi Pariwisata Dinas Budaya Pemuda Dan Olahraga Kabupaten Purwakarta
}

\author{
Kukoh Mey Ariyanto ${ }^{* 1}$, Rendi Sugiarta ${ }^{2}$, Rifki Maulana Yoga ${ }^{3}$ \\ ${ }^{1,3}$ Program Studi Teknik Informatika, Fakultas Sains dan Teknologi, Universitas Raharja \\ ${ }^{2}$ Program Studi Manajemen Informatika, Fakultas Sains dan Teknologi, Universitas Raharja \\ E-Mail: *11 kukoh@ raharja.info,${ }^{2}$ rendi.sugiarta@ raharja.info, ${ }^{3}$ rifki.maulana@ raharja.info
}

\begin{abstract}
Abstrak
Dalam bidang informasi audio visual merupakan penyajian informasi yang sangat menyenangkan dan menarik dalam proses penyampaiannya. Informasi tidak berfungsi dengan baik jika tidak ada media pendukung yang kuat untuk menginformasikan suatu produk atau jasa. Media video merupakan media yang paling lengkap, karena video memiliki unsur audio visual dan multimedia siaran yang merupakan perantara dan penyerapannya melalui gambar, teks, audio, dan video yang dapat memberikan visibilitas dan pendengaran yang memiliki daya tarik sangat menarik. Permasalahan yang ada yaitu Dinas wisata Purwakarta hanya menggunakan media foto dan video sebagai wadah media informasi, akan tetapi kurang terupdetnya sebuah informasi, maka akan dikhawatirkan kurang mencapai target untuk memberikan informasi tentang keindahan dan keunikannya. Oleh karena itu media video dirancang untuk mendukung informasi dan promosi dalam meningkatkan daya tarik pengunjung wisata di kabupaten Purwakarta. Metode penelitian ini menggunakan wawancara, observasi, studi pustaka, dan konsep produksi media (KPM). Hasil dari penelitian ini adalah menghasilkan objek wisata yang berbeda dengan kualitas terbaik, serta memadukan berbagai efek visual secara modern namun tradisional, kokoh, efisien dan efektif. Dan manfaat dari penelitian ini adalah terdapat hasil penelitian video informatif yang dapat menarik minat masyarakat untuk membentuk Dinas Pemuda, Olahraga, Pariwisata dan Kebudayaan Kabupaten Purwakarta.
\end{abstract}

Kata kunci - Informasi,Video,Pariwisata

\begin{abstract}
In the field of audio-visual information, it is a very fun and interesting presentation of information in the delivery process. Information does not function properly if there is no strong supporting media to inform a product or service. Video media is the most complete media, because video has elements of audio-visual and broadcast multimedia which are intermediaries and absorption through images, text, audio, and video which can provide visibility and hearing which has very attractive appeal. The problem is that the Purwakarta tourism office only uses photos and videos as a medium for information media, but the lack of information is lacking, so it is feared that it will not reach the target to provide information about its beauty and uniqueness. Therefore, video media is designed to support information and promotion in increasing the attraction of tourist visitors in Purwakarta district. This research method uses interviews, observation, literature study, and the concept of media production (KPM). The result of this research is to produce different tourist objects with the best quality, and to combine various visual effects in a modern yet traditional, sturdy, efficient and effective manner. And the benefit of this research is that there are informative video research results that can attract public interest to form the Department of Youth, Sports, Tourism and Culture of Purwakarta Regency.
\end{abstract}

Keywords - Information, Video, Tourism 


\section{PENDAHULUAN}

Di bidang informasi audio visual merupakan penyajian informasi yang sangat efektif dan menarik dalam proses penyampaiannya. Informasi tidak berfungsi dengan baik jika tidak ada media pendukung yang kuat untuk menginformasikan suatu produk atau jasa.

Media informasi saat ini merupakan sekumpulan petunjuk yang telah diproses dan akan diolah menjadi format data guna memperoleh informasi yang baik bagi siapa saja yang membutuhkannya. Informasi merupakan data yang telah diolah dan digunakan oleh individu, organisasi, atau siapapun yang membutuhkannya dan data tersebut menjadi suatu bentuk sehingga berguna dalam pengambilan keputusan. ${ }^{[1]}$

Video adalah kombinasi dari gambar diam yang berurutan pada suatu waktu dalam langkah khusus yang meliputi teknologi untuk, pemrosesan, perekaman dan, transmisi, penataan ulang gambar bergerak. Biasanya menggunakan pita seluloid, sinyal elektronik, atau media digital dengan semburan gambar digital yang muncul secara cepat dengan kecepatan tetap. Dalam komposisi video, nama ukuran untuk menghitung bingkai yang ditampilkan rata-rata disebut frame per second (FPS). Setiap bingkai adalah gambar kamera digital yang terdiri dari gambar piksel raster ${ }^{[2]}$

Dan pariwisata merupakan bagian yang tidak terpisahkan dari dunia pariwisata. Pariwisata sangat beragam, muda-tua, miskin-kaya, asing, semua mempunyai keinginan dan harapan yang berbeda, perkembangan perindustrian pariwisata di Indonesia memiliki kemajuan yang sangat pesat. Tampaknya lebih banyak jenis pariwisata yang tersedia. Jenis pariwisata yang dimaksud termasuk wisata budaya, yaitu perjalanan yang dilakukan oleh seorang wisatawan atau sekelompok orang yang mengunjungi suatu tempat wisata untuk mempelajari budaya dengan memanfaatkan kekuatan budaya tempat yang dikunjungi atau sebagai tempat hiburan untuk mengisi waktu luang. ${ }^{[3]}$

Sekarang ini bukan saja perusahaan yang menyajikan media video dalam memberikan informasi dan menpromosikan keberadaan sebuah instansi tersebut. Meskipun demikian, tempat wisata pun mulai memanfaatkan media promosi dan informasi dengan menggunakan perantara video dalam keindahan dan keunikan tempat wisatanya. Video merupakan perantara yang paling efektif, karena video memiliki elemen visualisasi yang jelas dan elemen tersebut adalah image, text, dan sound effect. Dengan kesadaran akan pentingnya informasi, peran dan keberadaan Dinas Pemuda, Olahraga, Pariwisata dan Kebudayaan Kabupaten Purwakarta untuk mempertegas tugas pokok dan fungsi suatu organisasi dalam rangka instansi pemerintah melaksanakan amanah yang terungkap dalam ketentuan. penggerak roda pemerintahan, pemuda, olah raga, pariwisata dan budaya di wilayah Kabupaten Purwakarta. dengan kekuatan berbagai potensi dengan prinsip efisiensi dan efektifitas bersama dengan kreasi penuh dalam kerangka demokrasi untuk mengabdi pada negara. Disporaparbud berlokasi di Sindangkasih, Kecamatan Purwakarta, Kabupaten Purwakarta, Jawa Barat. Seiring dengan perkembangan teknologi dan berjalannya waktu, Disporaparbud Purwakarta terus berupaya untuk meningkatkan kualitasnya agar dapat memuaskan masyarakat dengan memiliki inovasi-inovasi yang memungkinkan masyarakat untuk secara leluasa mengekspresikan ide, konsep dan pendapat dalam pembuatan berbagai jenis informasi dan aplikasi. mereka ke produk digital yang diinginkan. publik.

Selama ini organisasi yang bergerak di bidang olahraga, pariwisata dan budaya anak muda ini hanya menggunakan media informasi berupa foto dan video kegiatan di beberapa media sosial, seperti yang sudah dimiliki oleh intansi pengolahan wisata lain. Jika Disporaparbud Purwakarta baru menggunakan foto dan video sebagai media informasi tersebut tidak mencapai target yang maksimal dan tidak dapat bersaing dengan instansi pengolahan wisata yang lebih baik yang mampu memberikan berita dan informasi menarik pada video digital dan media sosial lainnya. Oleh karena itu, Disporaparbud Kabupaten Purwakarta membutuhkan video informasi digital yang lebih terbaru sebagai media informasi dan berita ke berbagai relasi dan masyarakat luas sehingga sangat membantu instansi dalam menginformasikan dan menghubungkan instansi dengan masyarakat secara efektif. Sehingga 
masyarakat akan semakin tertarik dengan kualitas yang dihasilkan Disporaparbud Kabupaten Purwakarta.

\section{METODE PENELITIAN}

Metode penelitian yang digunakan untuk melengkapi dan memperoleh data yang dibutuhkan dalam media informasi pariwisata dinas budaya pemuda dan olahraga Kabupaten purwakarta (1) Metode Wawancara. cara ini dilakukan dengan bertanya jawab secara langsung antara peneliti dengan kepala bidang pariwisata disporaparbud dengan bertujuan untuk mengumpulkan data dan informasi perencanaan dengan tepat sesuai kondisi yang berlaku. (2) Metode Observasi (Pengamatan Langsung) yang dilakukan untuk menerima data agar perancangan informasi yang akan dibuat dan membuat catatan berkala sampai unsur-unsur yang sudah terperinci secara langsung pada objek wisata di kabupaten Purwakarta (3) Studi pustaka merupakan kegiatan mengumpulkan teori yang bersangkutan dengan topik atau masalah yang menjadi objek penelitian yang saat ini dilakukan. Desain Media (4) Analisis Perancangan Video Wisata pada Dinas Pemuda, Olahraga, Pariwisata dan Kebudayaan Kabupaten Purwakarta Sebagai Informasi Penunjang Menggunakan Aplikasi Komputer Grafis, Menggunakan Software Adobe Premiere Pro 2018, Adobe After Effects Pro 2019 dan Adobe Audition CS6 (5) Tahap konsep produksi media (KPM) merupakan bagian darI Pra-produksi, Produksi, Pasca-produksi yang memiliki beberapa tahapan berupa ide dan gagasan, narasi, storyboard, perancangan multimedia, dan penyusunan crew.

\section{Literature Review}

Penelitian Sidik, dkk (2019) ${ }^{[4]}$ "Video Pinang TV Informasi di Kabupaten Pinang Kota Tangerang" penulis menjelaskan informasi saat ini sangat untuk membeikan informasi penting kepada masyarakat umum, kecamatan pinang merupakan salah satu kecamatan di wilayah Kota Tangerang. Kecamatan Pinang adalah satu-satunya agensi yang memiliki Pinang TV. Tujuan dari penelitian ini menyampaikan informasi melalui program Pinang TV kepada masyarakat. Penelitian yang dimanfaatkan dalam penelitian ini meliputi metode pengumpulan data, analisis desain media, dan konsep produksi media (KPM) yang meliputi: praproduksi, produksi dan pascaproduksi.

Penelitian oleh Al Husain (2019) ${ }^{[5]}$, "Perancangan Informasi Objek Wisata Curug Layung Melalui Media Video Dokumenter" penelitian ini mengjelaskan bahwa Perancangan ini dilakukan dengan melihat secara langsung dan mengetahui permasalahan apa saja yang ada disekitar masyarakat kemudian mencari jawaban dan solusi dari permasalahan tersebut. Maksud dan tujuan perancangan yang dilakukan adalah untuk dapat menyelesaikan suatu masalah melalui perancangan media pada suatu objek tepatnya pada suatu objek wisata. Obyek wisata adalah segala tempat atau kondisi alam yang telah membangun dan mengembangkan sumber daya wisata sehingga mempunyai daya tarik.

Penelitian yang dilakukan Apriliani, dkk (2019: 1) ${ }^{[6]}$, "Pembuatan Video Profil dengan Efek Vintage Kampung Wisata Adat Sengkoah sebagai Media Informasi" Peneltian ini menjelaskan Kabupaten Lombok Tengah merupakan salah satu kabupaten yang mendukung terbentuknya Desa Wisata. Salah satu Desa Wisata yang belum lama ini dirintis yaitu Kampung Wisata Adat Sengkoah. Kampung ini belum banyak diketahui masyarakat luas karena penyebaran informasi. Sebelumnya penyebaran informasi hanya melalui laman facebook dan artikel internet. Dalam rangka memperkenalkan Kampung Wisata Adat Sengkoah ini, peneliti membuat sebuah video profil dengan efek vintage. Dimana efek vintage ini akan menguatkan kesan masa lampau pada bagian video yang diperlukan.

Penelitian oleh Sasongko (2016: 2) ${ }^{[7]}$,"Media Promosi Pariwisata Kota Tangerang dalam Bentuk Video Digital pada Dinas Porparekraf" penelitian ini menjelaskan Untuk menyampaikan sebuah video pariwisata Kota Tangerang yang informatif, dan perlu memiliki video perkembangan pariwisata Kota Tangerang yang memiliki informasi terkini mengenai 
perkembangan pariwisata Kota Tangerang saat ini, karena media audio visual memuat rangkaian gambar, teks, video dan suara. yang berjalan untuk tujuan informasi dalam memperkenalkan kota tangerang yang memiliki sejarah panjang dan menyimpan berbagai macam tujuan wisata, baik wisata alam, wisata budaya, wisata kuliner, dan wisata religi yang menarik yang dijadikan sebagai destinasi wisata, untuk mendukung promosi pariwisata yang lebih baik di Kota Tangerang.

\section{HASIL DAN PEMBAHASAN}

Konsep Produksi Media merupakan teori dalam mengefektifkan produk dengan menggunakan teknik audio visual dan multimedia siaran yang mengatur perantara dan penyerapannya melalui gambar, teks, audio, dan video yang dapat memberikan visibilitas dan pendengaran yang memiliki daya tarik yang sangat menarik.

\subsection{Pra-produksi}

Pra produksi merupakan tahapan persiapan untuk merencanakan hal-hal yang diperlukan dalam suatu proses dalam melaksanakan suatu kegiatan produksi.

\section{Ide dan Gagasan}

Secara sederhana ide dapat diartikan sebuah rencana awal. Selama ide/gagasan belum dapat dituangkan menjadi suatu konsep dengan tulisan maupun gambar yang nyata maka tahapan preproduction selanjutnya belum dapat dilakukan. Dinas Kepemudaan Olahraga Pariwisata Dan Kebudayaan Kabupaten Purwakarta bertujuan memperluas informasi khususnya pada bidang pariwisata, dalam hal ini akan menjadi ide untuk merancang sebuah video informasi tentang pariwisata oleh Dinas Kepemudaan Olahraga Pariwisata Dan Kebudayaan Kabupaten Purwakarta.

\section{Sinopsis atau Cerita}

Sinopsis merupakan inti cerita yang dibentuk menjadi cerita singkat, padat dan jelas tanpa menghilangkan unsur penting dalam keseluruhan ceritanya. Sinopsis media video informasi wisata pada Dinas Kepemudaan Olahraga Pariwisata dan Kebudayaan Kabupaten Purwakarta ini adalah :

"Kabupaten purwakarta saat ini telah bertranformasi menjadi daerah tujuan wisata bagi wisatawan di Jawa Barat bahkan nasional. Sehingga kini Purwakarta memiliki sebuah identitas kota wisata.

Beragam pilihan destinasi wisata terbesar di berbagai titik kota hingga ke pelosok desa, dengan semakin berkembangnya destinasi wisata di Purwakarta maka kunjungan wisatawan pun setiap tahunnya meningkat.

Purwakarta Pesona Sunda merupakan spirit pembangunan pariwisata Purwakarta berkelanjutan yang berbasis kearifan lokal namun berdaya saing global sehingga menjadikan Kabupaten Purwakarta sebagai kota wisata yang berkarakter”.

\section{Narasi}

Narasi ialah karangan atau pemikiran cerita untuk menyampaikan peristiwa atau peristiwa yang terjadi dalam suatu timeline dan sebagai media untuk mendukung efektifitas penyampaian informasi yang disampaikan dengan suara.

Ramainya suasana kota kecil ini / membuat hati ini ingin berkelana // dunia kerja tak selalu membuat hati ku tenang / sedangkan tuhan sudah menciptakan alam yang seperti anugerah bagiku // angin menggoda bulu bulu mataku / semua kisah kisahnya ku rajut dari berbagai hal menjadi album di memori otakku // Lalu lalang insan yg sibuk mengejar citanyal Akhirnya hari ini pun tiba/ Waktunya otak dan logika ku berkelana/ Menghirup segarnya sebagian kecil Purwakartal Menyajikan pemandangan yg berbedal Memusnahkan rasa gundah di lubuk hati/ Menyapa dengan ramah setiap insan yg datang/ 
Dibalut dengan wisatanya yg sangat indah/ Bagaimana bisa aku menyimpulkan dengan kata/ Semoga Purwakarta tetap istimewal

\section{Pembuatan Storyboard}

Storyboard merupakan urutan penggambaran atau sketsa dalam menyusun cerita yang berhubungan dalam naskah, sehingga naskah yang akan dibuat dapat memvisualisasikan cerita tersebut. Berikut ini adalah deskripsi storyboard informasi wisata pada Dinas Olahraga, Pariwisata dan Kebudayaan Pemuda Purwakarta(DISPORAPARBUD).

1. Menampilkan bukaan Bumper logo Kabupaten Purwakarta

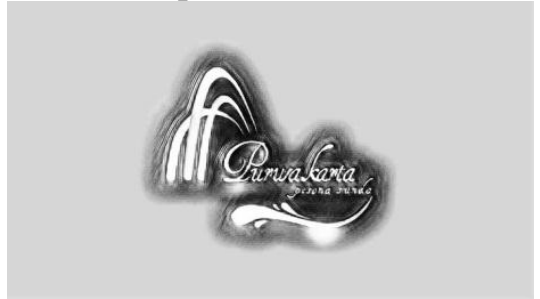

Gambar 4.1. Logo Bumper Kabupaten Purwakarta

3. Menampilkan video Talent duduk dan membuka laporan kerja yang rumit

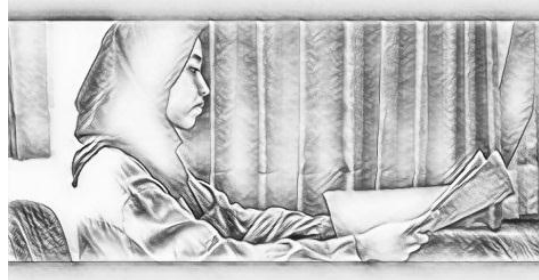

Gambar 4.3. Menampilkan video Talent duduk dan membuka laporan kerja yang rumit

5. Menampilkan Bakat persiapan dan berangkat berwisata ke Kabupaten Purwakarta

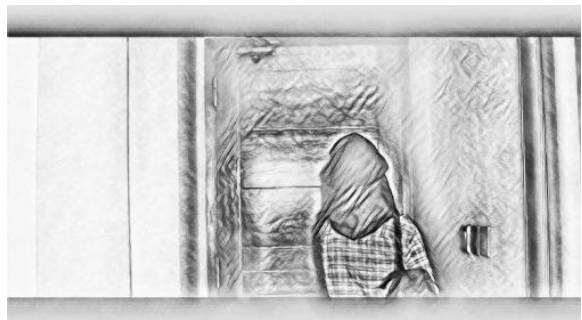

Gambar 4.5. Menampilkan Bakat persiapan dan berangkat berwisata ke Kabupaten Purwakarta
2. Menampilkan slogan Bumper Purwakarta Pesona Sunda

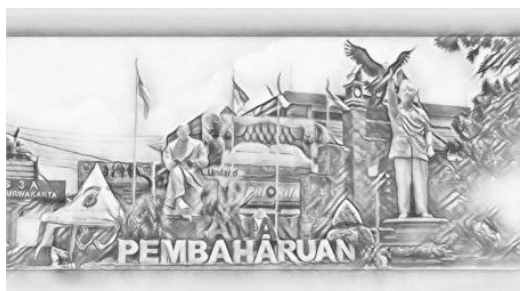

Gambar 4.2. slogan Bumper Purwakarta Pesona Sunda

4. Menampilkan video Bakat mengambil pakaian di ruang ganti

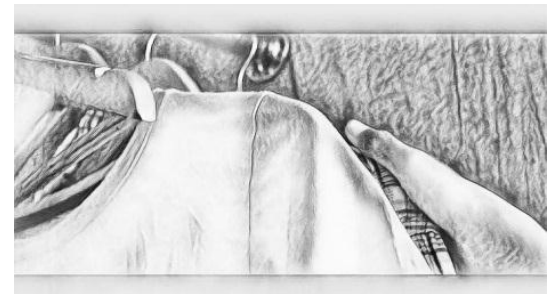

Gambar 4.4. Menampilkan video Bakat mengambil pakaian di ruang ganti

6. Menampilkan video berjudul "Ayo Main ke Purwakarta

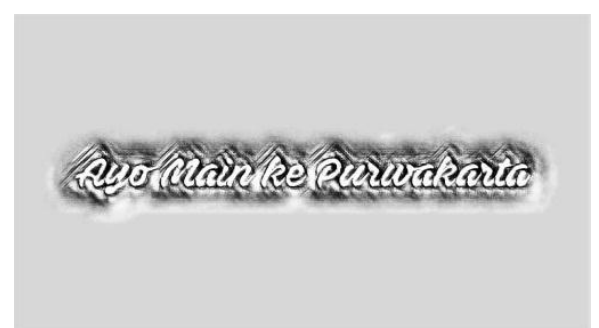

Gambar 4.6. Menampilkan video berjudul "Ayo Main ke Purwakarta 
7. Menampilkan video stasiun Purwakarta

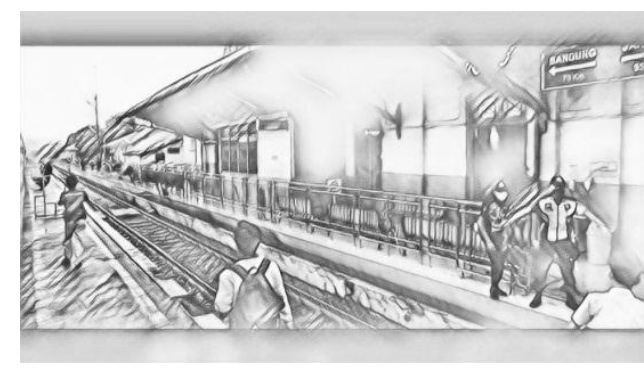

Gambar 4.7. Menampilkan video stasiun Purwakarta

9. Menampilkan video wisata Situ Wanayasa

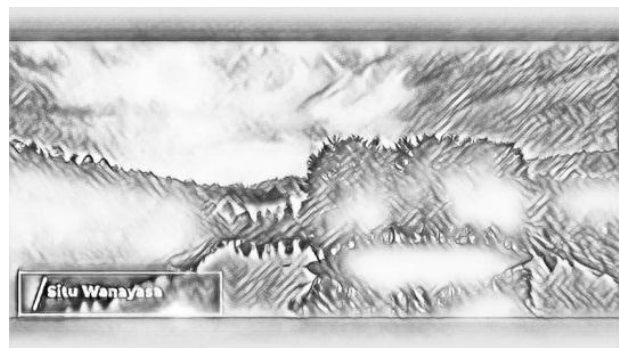

Gambar 4.9. Menampilkan video wisata Situ Wanayasa

\section{Menampilkan video wisata Parang Gombong}

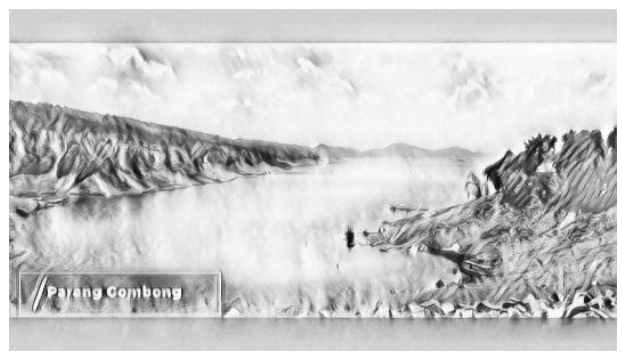

Gambar 4.11. Menampilkan video wisata Parang Gombong
8. Menampilkan bakat keluar dari stasiun purwakarta

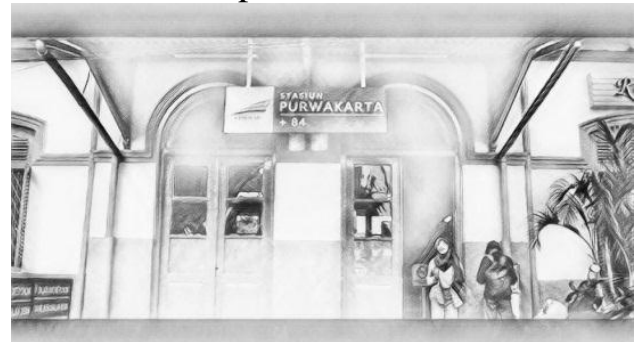

Gambar 4.8. Menampilkan bakat keluar dari stasiun purwakarta

10. Menampilkan video wisata Hidden Valley Hills

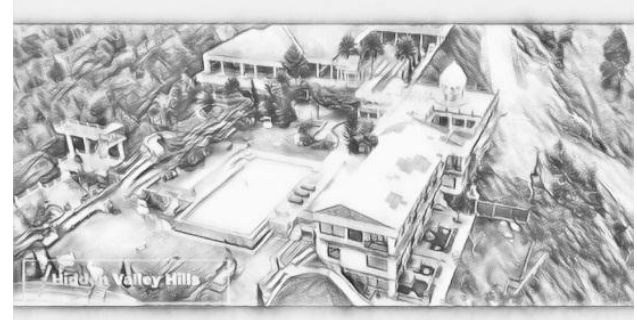

Gambar 4.10. Menampilkan video wisata Hidden Valley Hills

12. Menampilkan video outro bumper (logo Kabupaten Purwakarta dan slogan Purwakarta Pesona Sunda)

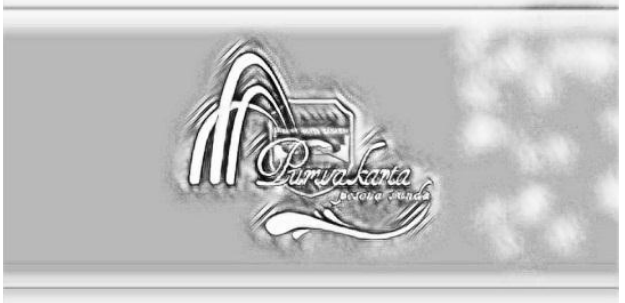

Gambar 4.12. Menampilkan video outro bumper (logo Kabupaten Purwakarta dan slogan Purwakarta Pesona Sunda)

\section{Script Writing}

Penulisan Naskah, yaitu membuat desain naskah penulisan secara detail guna memudahkan dalam proses pengeditan. Berisi tampilan awal hingga menyelesaikan tampilan konten video dan audio yang digunakan dalam proses pengeditan.

Tabel 1. Script Writing

\begin{tabular}{|c|l|c|}
\hline NO. & \multicolumn{1}{|c|}{ Visual } & Audio \\
\hline 1. & $\begin{array}{l}\text { Menampilkan Bumper opening logo Kabupaten } \\
\text { Purwakarta }\end{array}$ & Audio \\
\hline 2. & Menampilkan Bumper slogan Purwakarta Pesona Sunda & Audio \\
\hline
\end{tabular}




\begin{tabular}{|c|l|c|}
\hline 3. & $\begin{array}{l}\text { Menampilkan video opening objek objek pariwisata } \\
\text { Kabupaten Purwakarta }\end{array}$ & Audio \\
\hline 4. & $\begin{array}{l}\text { Menampilkan video Talent } \text { duduk dan membuka laporan } \\
\text { kerja yang rumit }\end{array}$ & $\begin{array}{c}\text { Audio + } \\
\text { Dubbing }\end{array}$ \\
\hline 5. & $\begin{array}{l}\text { Menampilkan video Talent mengambil pakaian di ruang } \\
\text { ganti }\end{array}$ & $\begin{array}{c}\text { Audio + } \\
\text { Dubbing }\end{array}$ \\
\hline 6. & $\begin{array}{l}\text { Menampilkan Talent persiapan dan berangkat berwisata } \\
\text { ke Kabupaten Purwakarta }\end{array}$ & $\begin{array}{c}\text { Audio + } \\
\text { Dubbing }\end{array}$ \\
\hline 7. & Menampilkan video judul “Ayo Main ke Purwakarta" & Audio \\
\hline 8. & Menampilkan video stasiun Purwakarta & Audio \\
\hline 9. & Menampilkan talent keluar dari stasiun purwakarta & Audio \\
\hline 10. & Menampilkan video wisata Situ Wanayasa & Audio \\
\hline 11. & Menampilkan video wisata Hidden Valley Hills & Audio \\
\hline 12. & Menampilkan video wisata Sasak Panyawangan & Audio \\
\hline 13. & Menampilkan video wisata Parang Gombong & Audio \\
\hline 14. & Menampilkan video wisata Grama Tirta Jatiluhur & Audio \\
\hline 15. & Menampilkan video Timelapse senja di Grama Tirta & Audio \\
\hline 16. & $\begin{array}{l}\text { Menampilkan video } \text { outro Bumper (logo Kabupaten } \\
\text { Purwakarta dan slogan Purwakarta Pesona Sunda) }\end{array}$ & Audio \\
\hline
\end{tabular}

\section{Rundown}

Tabel 2. Rundown

\begin{tabular}{|c|c|c|c|c|c|}
\hline No. & Scene & Location & Duration & $\begin{array}{l}\text { INT / } \\
\text { EXT }\end{array}$ & Description \\
\hline 1. & 4 & $\begin{array}{l}\text { Menampilkan video Talent } \\
\text { duduk dan membuka } \\
\text { laporan kerja yang rumit }\end{array}$ & $\begin{array}{c}00: 29- \\
00: 54\end{array}$ & INT & $\begin{array}{c}\text { keadaan lelahnya Talent } \\
\text { dengan dunia kerja }\end{array}$ \\
\hline 2. & 5 & $\begin{array}{l}\text { Menampilkan video Talent } \\
\text { nengambil pakaian di ruang } \\
\text { ganti }\end{array}$ & $\begin{array}{c}00: 55- \\
01: 02\end{array}$ & INT & $\begin{array}{c}\text { Rasa gembira ketika akan } \\
\text { pergi travelling }\end{array}$ \\
\hline 3. & 6 & $\begin{array}{c}\text { Menampilkan Talent } \\
\text { persiapan dan berangkat } \\
\text { berwisata ke Kabupaten } \\
\text { Purwakarta }\end{array}$ & $\begin{array}{c}01: 04- \\
01: 22\end{array}$ & INT & $\begin{array}{c}\text { Menampilkan Talent } \\
\text { persiapan dan berangkat } \\
\text { berwisata ke Kabupaten } \\
\text { Purwakarta }\end{array}$ \\
\hline 4. & 8 & $\begin{array}{c}\text { Menampilkan video stasiun } \\
\text { Purwakarta }\end{array}$ & $\begin{array}{c}01: 29- \\
01: 33\end{array}$ & EXT & $\begin{array}{l}\text { Suasana keramaian } \\
\text { stasiun Purwakarta }\end{array}$ \\
\hline 5. & 9 & $\begin{array}{l}\text { Menampilkan talent keluar } \\
\text { dari stasiun purwakarta }\end{array}$ & $\begin{array}{c}01: 34- \\
01: 37\end{array}$ & EXT & $\begin{array}{c}\text { Awalan melihat } \\
\text { keindahan kabupaten } \\
\text { purwakarta }\end{array}$ \\
\hline 6. & 10 & $\begin{array}{c}\text { Menampilkan video wisata } \\
\text { Situ Wanayasa }\end{array}$ & $\begin{array}{c}01: 46- \\
02: 02\end{array}$ & EXT & $\begin{array}{c}\text { Suasana wisata situ } \\
\text { wanayasa }\end{array}$ \\
\hline 7. & 11 & $\begin{array}{c}\text { Menampilkan video wisata } \\
\text { Hidden Valley Hills }\end{array}$ & $\begin{array}{l}02: 05- \\
02: 17\end{array}$ & EXT & $\begin{array}{c}\text { Suasana wisata hidden } \\
\text { valley hills }\end{array}$ \\
\hline 8. & 12 & $\begin{array}{c}\text { Menampilkan video wisata } \\
\text { Sasak Panyawangan }\end{array}$ & $\begin{array}{c}02: 18- \\
02: 44\end{array}$ & EXT & $\begin{array}{c}\text { Suasana wisata sasak } \\
\text { panyawangan }\end{array}$ \\
\hline 9. & 13 & $\begin{array}{l}\text { Menampilkan video wisata } \\
\text { Parang Gombong }\end{array}$ & $\begin{array}{c}02: 44- \\
03: 09\end{array}$ & EXT & $\begin{array}{c}\text { Suasana wisata parang } \\
\text { gombong }\end{array}$ \\
\hline 10. & 14 & $\begin{array}{c}\text { Menampilkan video wisata } \\
\text { Grama Tirta Jatiluhur }\end{array}$ & $\begin{array}{c}03: 10- \\
03: 20\end{array}$ & EXT & $\begin{array}{c}\text { Keindahan suasana } \\
\text { wisata Grama Tirta } \\
\text { Jatiluhur }\end{array}$ \\
\hline 11 & 15 & Menampilkan video & $03: 21-$ & EXT & Suasana indahnya \\
\hline
\end{tabular}


Print ISSN: 2723-1992

Online ISSN: 2723-200X

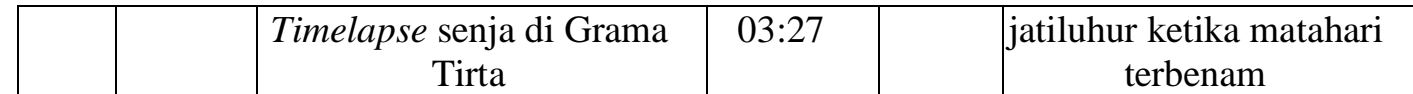

7. Penyusunan Crew

Kru produksi yang terlibat dalam video informasi wisata di Dinas Pemuda Olahraga Pariwisata dan Kebudayaan Kabupaten Purwakarta.

Tabel 3. Susunan Crew dan Talent

\begin{tabular}{|c|l|l|}
\hline No. & \multicolumn{1}{|c|}{ Jabatan } & \multicolumn{1}{c|}{ Nama } \\
\hline 1. & Sutradara / Director & Rifki Maulana Yoga \\
\hline 2. & DOP (Direct Of Photography) & Rifki Maulana Yoga \\
\hline 3. & Camera Person 1 & Rifki Maulana Yoga \\
\hline 4. & Camera Person 2 & Taufiq Kurniawan \\
\hline 5. & Camera Person 3 & Muhammad Harun Alrasyid \\
\hline 6. & Editor & Rifki Maulana Yoga \\
\hline 7. & Script Writing & Rifki Maulana Yoga \\
\hline 8. & Dubber & Malyandri Samsiah \\
\hline 9. & Pemain / Talent & Malyandri Samsiah \\
\hline
\end{tabular}

\section{Software}

Pada proses produksi inilah desain efek khusus dibuat dengan menggunakan Software Adobe Audition, After Premiere pro cc 2019 dan After Effect Pro cc 2018 yang menunjukan produk atau hasil perkembangan teknologi.

9. Time Schedule

Tabel 4. Time Schedule

\begin{tabular}{|c|c|c|c|c|c|c|c|c|c|c|c|c|c|c|c|c|c|c|c|c|c|}
\hline \multirow{2}{*}{\multicolumn{2}{|c|}{ Tahapan }} & \multicolumn{4}{|c|}{$\begin{array}{l}\text { Agustus } \\
2020\end{array}$} & \multicolumn{4}{|c|}{$\begin{array}{c}\text { September } \\
2020\end{array}$} & \multicolumn{4}{|c|}{$\begin{array}{c}\text { Oktober } \\
2020\end{array}$} & \multicolumn{4}{|c|}{$\begin{array}{c}\text { November } \\
2020\end{array}$} & \multicolumn{4}{|c|}{$\begin{array}{l}\text { Desember } \\
2021\end{array}$} \\
\hline & & 1 & 2 & 3 & 4 & 1 & 2 & 3 & 4 & 1 & 2 & 3 & 4 & 1 & 2 & 3 & 4 & 1 & 2 & 3 & 4 \\
\hline \multirow{12}{*}{$\begin{array}{l}\tilde{0} \\
0 \\
0 \\
0 \\
0 \\
0 \\
0 \\
0\end{array}$} & Pengajuan observasi & & & & & & & & & & & & & & & & & & & & \\
\hline & Pengumpulan Data & & & & & & & & & & & & & & & & & & & & \\
\hline & Analisis Data & & & & & & & & & & & & & & & & & & & & \\
\hline & Ide / Gagasan & & & & & & & & & & & & & & & & & & & & \\
\hline & Sinopsis / Cerita & & & & & & & & & & & & & & & & & & & & \\
\hline & Narasi & & & & & & & & & & & & & & & & & & & & \\
\hline & $\begin{array}{l}\text { Pembuatan } \\
\text { Storyboard }\end{array}$ & & & & & & & & & & & & & & & & & & & & \\
\hline & Script writing & & & & & & & & & & & & & & & & & & & & \\
\hline & Penyusunan $\mathrm{Crew}$ & & & & & & & & & & & & & & & & & & & & \\
\hline & Time Schedule & & & & & & & & & & & & & & & & & & & & \\
\hline & Anggaran / Budget & & & & & & & & & & & & & & & & & & & & \\
\hline & $\begin{array}{l}\text { Peralatan Yang } \\
\text { Digunakan }\end{array}$ & & & & & & & & & & & & & & & & & & & & \\
\hline \multirow{4}{*}{ 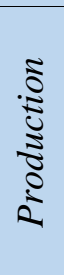 } & $\begin{array}{l}\text { Perencaaan } \\
\text { Multimedia }\end{array}$ & & & & & & & & & & & & & & & & & & & & \\
\hline & Perencanaan Audio & & & & & & & & & & & & & & & & & & & & \\
\hline & Perencanaan Visual & & & & & & & & & & & & & & & & & & & & \\
\hline & $\begin{array}{r}\text { Perencanaan } \\
\text { Broadcasting }\end{array}$ & & & & & & & & & & & & & & & & & & & & \\
\hline \multirow{2}{*}{$\stackrel{\bar{z}}{0}$} & Digitizing & & & & & & & & & & & & & & & & & & & & \\
\hline & Editing & & & & & & & & & & & & & & & & & & & & \\
\hline
\end{tabular}




\begin{tabular}{|c|c|l|l|l|l|l|l|l|l|l|l|l|l|l|l|l|l|l|l|l|l|}
\hline Finishing & Tahap Keluaran & & & & & & & & & & & & & & & & & & & & \\
\hline & Segmen Pasar & & & & & & & & & & & & & & & & & & & \\
\hline
\end{tabular}

10. Anggaran atau Budget

Anggaran adalah keuangan yang dikeluarkan untuk pembuatan sebuah project. Berikut ini adalah adalah anggaran dalam pembuatan media video profile Dinas Kepemudaan Olahraga Pariwisata dan Kebudayaan Kabupaten Purwakarta.

Tabel 5. Anggaran atau Budget

\begin{tabular}{|c|c|c|c|}
\hline No. & Alat Produksi & Ket & Biaya Produksi \\
\hline 1. & Survey lokasi & 3 Hari & Rp. 800.000 \\
\hline 2. & Sewa mobil & 10 Hari & Rp. 1.000 .000 \\
\hline 3. & Transport & 10 Hari & Rp. 1.138 .500 \\
\hline 4. & Akomodasi penginapan & 10 Hari & Rp. 700.000 \\
\hline 5. & Akomodasi di lapangan & 10 Hari & Rp. 973.200 \\
\hline 6. & Camera Canon DSLR (60D) & Pinjam & - \\
\hline 7. & Camera Canon DSLR (1100D) & Pinjam & - \\
\hline 8. & Camera Canon DSLR (650D) & Pribadi & - \\
\hline 9. & Lensa standar (Kit $18-55 \mathrm{~mm}$ ) & Pribadi & - \\
\hline 10. & Lensa (fix 50mm) & Pinjam & - \\
\hline 11. & $\begin{array}{l}\text { Lensa (EF-S 10-18mm F/4.5-5.6 } 15 \\
\text { STM) }\end{array}$ & Pinjam & - \\
\hline 12. & Lensa wide makro $58 \mathrm{~mm}$ & Pribadi & - \\
\hline 13. & Drone (DJI Phantom 5) & sewa & $\begin{array}{l}2 \text { Baterai x } 1 \text { Hari } \\
@ \text { Rp. } 400.000\end{array}$ \\
\hline 14. & Tripod & Pribadi & - \\
\hline 15. & Monopod & Pribadi & - \\
\hline 16. & Lighting LED & Pribadi & - \\
\hline 17. & Kabel rol & Pribadi & - \\
\hline 18. & Payung & Payung & - \\
\hline 19. & DVD RW dan Cover & 3 pcs & $\begin{array}{l}@ \text { Rp. } 30.000 \times 3 \text { Pcs } \\
=\text { Rp. } 90.000\end{array}$ \\
\hline \multicolumn{3}{|c|}{ Total } & Rp. 5.101.500 \\
\hline
\end{tabular}

\subsection{Production}

Proses pembuatan film mulai dari cerita awal, ide, atau komisi, melalui penulisan naskah, perekaman, penyuntingan, penyutradaraan dan penyaringan produk, Dalam tahap produksi, keberadaan kru merupakan hal terpenting dalam menunjang kelancaran proses syuting, sehingga kru harus mengikuti tugas-tugas yang diberikan selama proses produksi syuting atau syuting video, ada hal yang membutuhkan persiapan yang baik, diantaranya : naskah dan papan cerita agar menjadi pedoman yang baik tentang apa yang harus dilakukan saat pengambilan gambar.

\subsubsection{Perancangan Multimedia}

Perencanaan multimedia ialah perancangan dalam menggabungkan dan memanfaatkan unsur gambar, text, dan suara dengan membuat kreativitas yang sesuai dengan tujuan pembuatan video informasi yang modern dan berkualitas dengan pembuatan 
video informasi pariwisata yang diusulkan untuk meningkatkan pengunjung dan masyarakat secara efektif dan efisien dalam pariwisata.

\subsubsection{Strategi Visual}

Strategi visual merupakan media pendukung kegiatan informasi dan promosi yang menyampaikan pesan dan kesan sehingga dapat memberikan bentuk pencitraan atau gambar yang divisualisasikan secara realistis pada video. Visualisasi tayangan video yang berbeda dengan menampilkan beberapa elemen sebagaimana kondisi Kabupaten Purwakarta, objek wisata Kabupaten Purwakarta, dan fasilitas yang ada di Kabupaten Purwakarta, semuanya didesain secara modern namun tradisional, kokoh, efisien dan efektif dalam mencapai targetnya.

\subsubsection{Peralatan yang digunakan}

Peralatan yang digunakan dalam pembuatan video informasi wisata pada Dinas Kepemudaan Olahraga Pariwisata dan Kebudayaan Kabupaten Purwakarta antara lain :

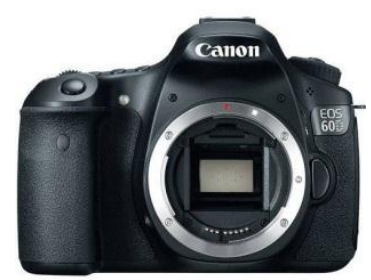

Gambar 4.13. Camera Canon DSLR (60D)

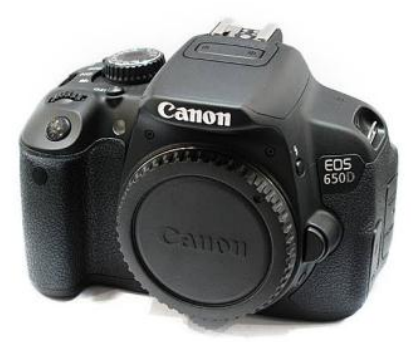

Gambar 4.15. Camera Canon DSLR (650D)

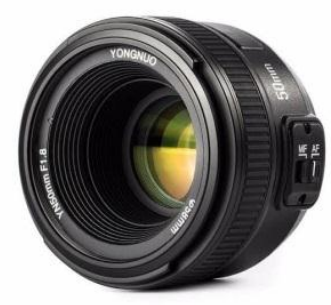

Gambar 4.17. Lensa (fix 50mm)

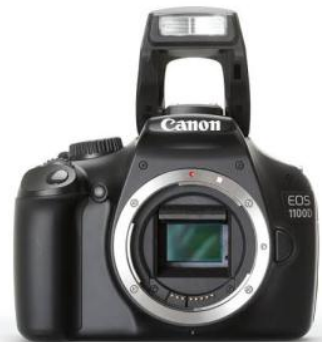

Gambar 4.14. Camera Canon DSLR (1100D)

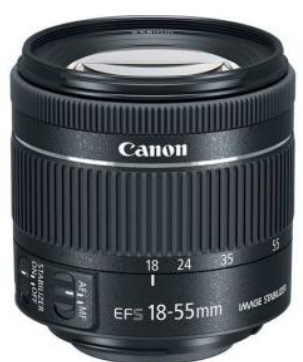

Gambar 4.16. Lensa standar (Kit 18-55mm)

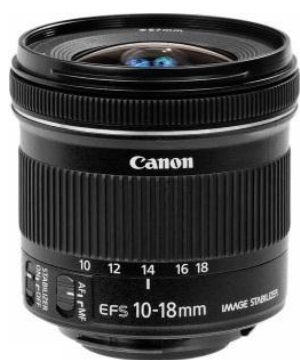

Gambar 4.18. Lensa (EF-5 10-18mm F/4.55.615 STM) 


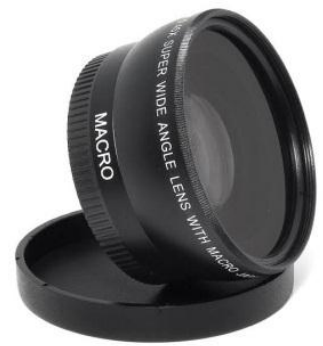

Gambar 4.19. Lensa wide makro 58mm

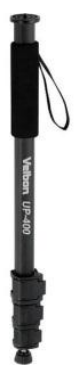

Gambar 4.21. Monopod

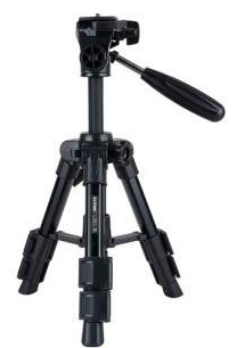

Gambar 4.20. Tripod

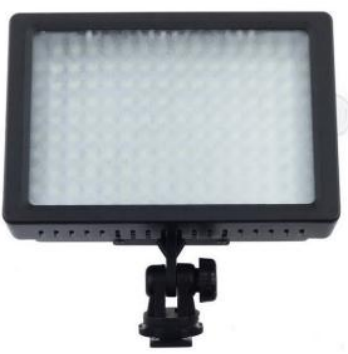

Gambar 4.22. Lighting LED

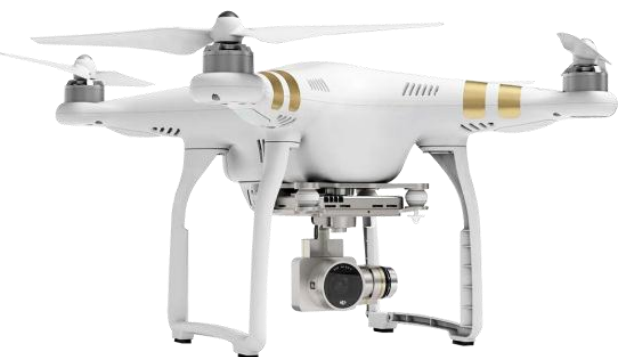

Gambar 4.23. Drone Panthom 5

\subsubsection{Program Visual}

Program visual merupakan tahapan pembuatan visual dengan bantuan teknologi komputer, guna memberikan gambaran nyata yang divisualisasikan pada video dan beberapa elemen visualisasi tayangan video yang berbeda dengan menampilkan suasana Kabupaten Purwakarta, obyek wisata Kabupaten Purwakarta, dan fasilitas yang ada. di Kabupaten Purwakarta semuanya dirancang dengan tepat, kokoh, efisien dan efektif.

1. Menampilkan bukaan Bumper logo Kabupaten Purwakarta

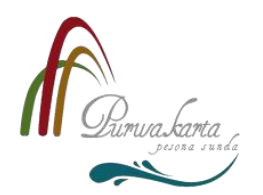

Gambar 4.24. Scene 1 / Logo Bumper Kabupaten Purwakarta
2. Menampilkan slogan Bumper Purwakarta Pesona Sunda

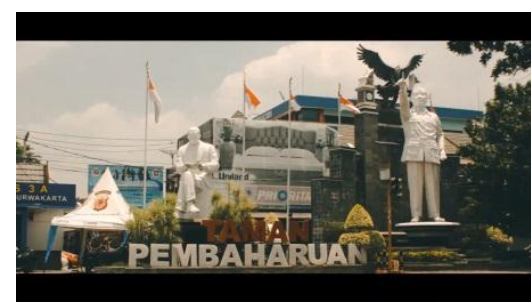

Gambar 4.25. Scene 2 / slogan Bumper Purwakarta Pesona Sunda 
Print ISSN: 2723-1992

Online ISSN: 2723-200X

3. Menampilkan video Talent duduk dan membuka laporan kerja yang rumit

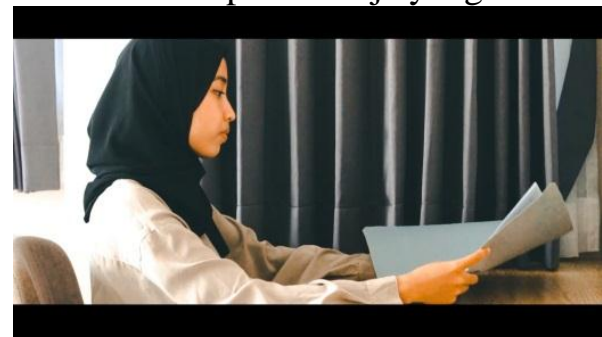

Gambar 4.26. Scene 3 / Menampilkan video Talent duduk dan membuka laporan kerja yang rumit

5. Menampilkan Bakat persiapan dan berangkat berwisata ke Kabupaten Purwakarta

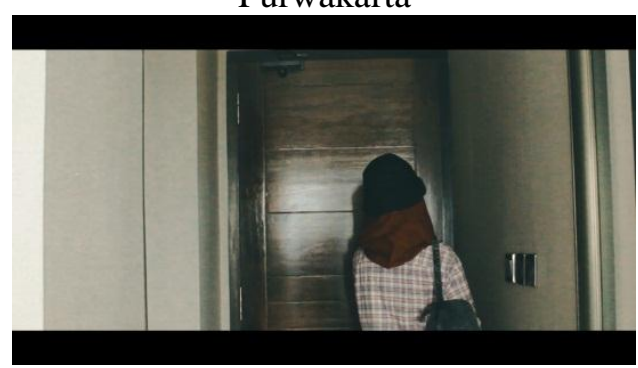

Gambar 4.28. Scene 5 / Menampilkan Bakat persiapan dan berangkat berwisata ke Kabupaten Purwakarta

7. Menampilkan video stasiun Purwakarta

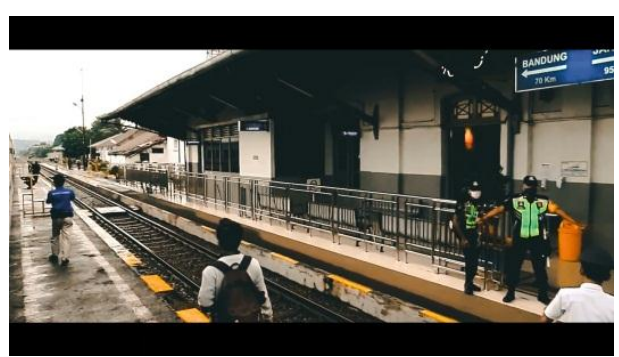

Gambar 4.30. Scene 7 / Menampilkan video stasiun Purwakarta
4. Menampilkan video Bakat mengambil pakaian di ruang ganti

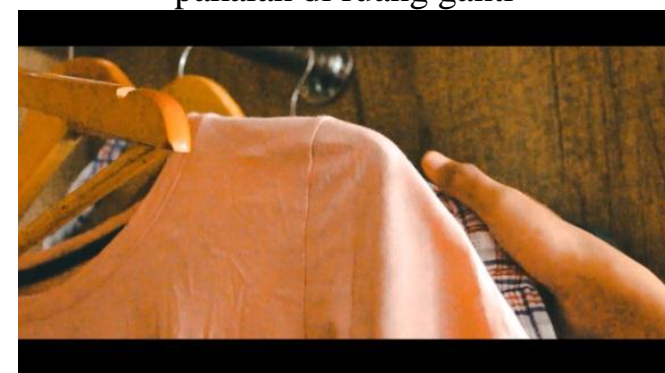

Gambar 4.27. Scene 4 / Menampilkan video Bakat mengambil pakaian di ruang ganti

6. Menampilkan video berjudul "Ayo Main ke Purwakarta

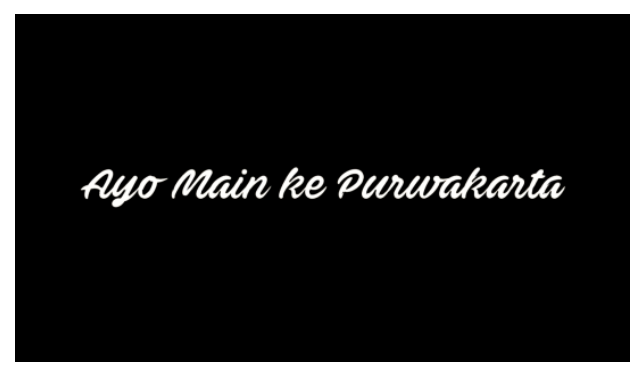

Gambar 4.29. Scene 6 / Menampilkan video berjudul "Ayo Main ke Purwakarta

8. Menampilkan bakat keluar dari stasiun purwakarta

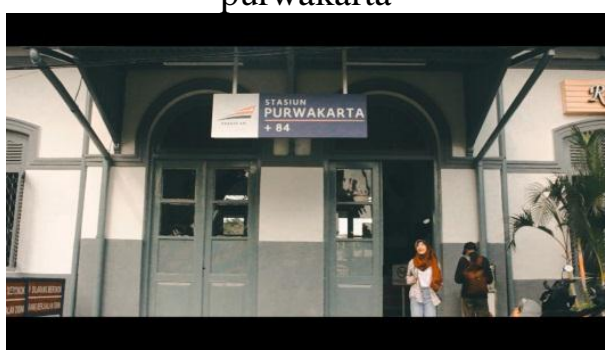

Gambar 4.31.Scene 8 / Menampilkan bakat keluar dari stasiun purwakarta 
9. Menampilkan video wisata Situ Wanayasa

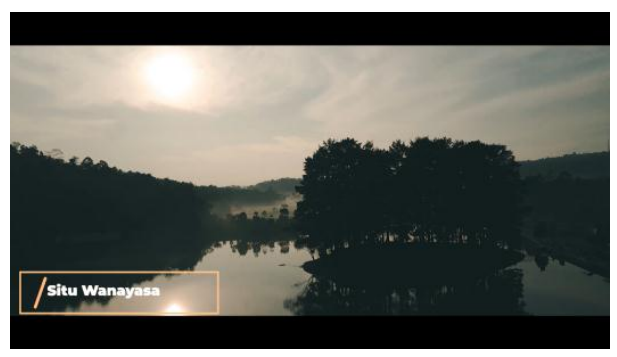

Gambar 4.32. Scene 9 / Menampilkan video wisata Situ Wanayasa

\section{Menampilkan video wisata Parang Gombong}

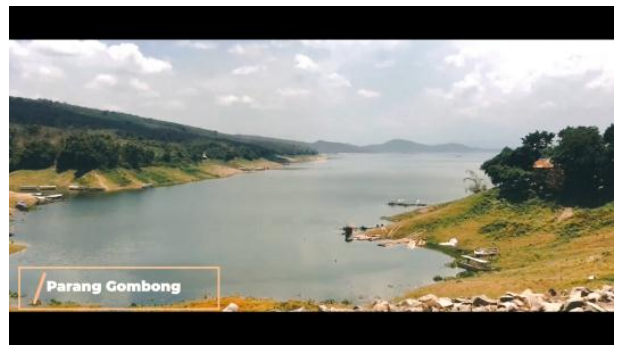

Gambar 4.34. Scene 11 / Menampilkan video wisata Parang Gombong
10. Menampilkan video wisata Hidden Valley Hills

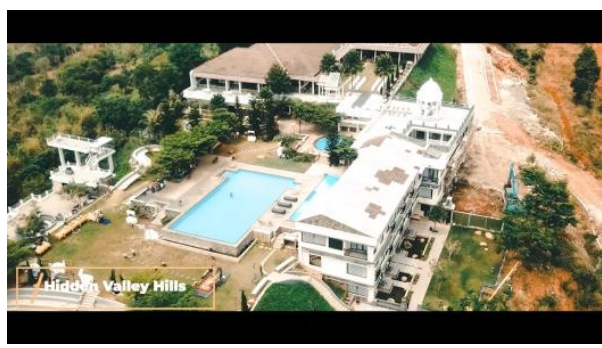

Gambar 4.33. Scene 10 / Menampilkan video wisata Hidden Valley Hills

12. Menampilkan video outro bumper (logo Kabupaten Purwakarta dan slogan Purwakarta Pesona Sunda)

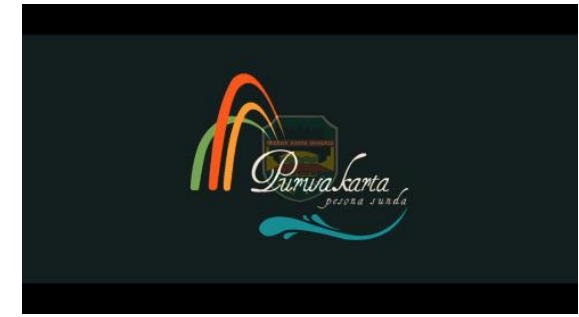

Gambar 4.35. Scene 12 / Menampilkan video outro bumper (logo Kabupaten Purwakarta dan slogan Purwakarta Pesona Sunda)

\subsection{Post-Production}

Merupakan proses penyelesaian dari rangkaian produksi (shoting) yang meliputi pengeditan gambar, penambahan judul, efek khusus, musik, efek suara, audio dubbing, dan keluaran ke media video. Pada eksploitasi pasca produksi, gambaran lengkap yang diperoleh dalam pembuatan media video digabungkan dan masuk ke dalam proses editor. Kegiatan penyaringan dan distribusi juga termasuk dalam proses pasca-produksi.

\section{Digitizing}

Digitizing adalah proses pemindahan gambar dari media seperti kamera ke dalam sebuah perangkat komputer ataupun laptop. Digitizing juga dapat diartikan transfer format film ke digital agar dapat diproses dalam mesin offline dan online.

\section{Editing}

Pada tahap editing video dilakukan pemotongan, pemilihan dan penyusunan hasil gambar shooting sesuai keinginan atau gaagsan sutradara sesuai dengan naskah dan storyboard.

\section{Mixing}

Mixing adalah proses editing dan penggabungan suara. Suara meliputi dubbing, music, dan effect suara. Sesudah proses mixing ini boleh dikatakan bagain yang penting dalam postproduction sudah selesai. Setelah melalui proses mixing ini, kemudian di render dan di ubah ke beberapa format file selanjutnya akan di pasarkan dan di sebarkan kepada masyarakat luas. 


\section{Finishing}

Tahap finishing ini merupakan tahap terkahir dalam proses pembuatan video Informasi ini. Pada tahap ini dilakukan proses export video dari Adobe Premiere Pro CC 2018 menjadi format video. Kemudian hasil export video di burning ke DVD dan di unggah ke youtube untuk menyebarkan video informasi ini kepada sasaran-sasaran yang telah ditentukan dalam potensi pasar.

\section{Tahap Keluaran}

Tahap exporting ini video mengikuti format format yang diinginkan mulai dari format video, format audio, dan nama keluaran dari video. Selanjutnya hasil export video akan di burning ke DVD, dan selanjutnya akan di upload ke dalam situs website maupun pemutaran video melalui YouTube.

\section{Segmen Pasar}

Segmen pasar adalah tahap paling akhir, di mana video profile ini diliris, di upload dan dipublikasikan ke publik. Diharapkan hasil video Informasi ini mencapai target dan meningkatkan presentase minat masyarakat dan wisatawan untuk berkunjung ke objek objek Kabupaten Purwakarta.

\section{KESIMPULAN}

Berdasarkan kesimpulan terkait penelitian yang dilakukan pada Dinas Olahraga Pemuda, Pariwisata dan Kebudayaan (DISPORAPARBUD) Kabupaten Purwakarta dengan membuat media informasi video sebagai informasi yang efektif perlu disampaikan melalui media informasi pariwisata di kabupaten Purwakarta yaitu memberikan segala informasi tentang pariwisata di Kabupaten Purwakarta dan memberikan penjelasan singkat yang dapat bermanfaat dan dapat dengan mudah dipahami oleh masyarakat luas.

\section{SARAN}

Dari hasil penelitian yang telah dilakukan, terdapat beberapa saran bagi DISPORAPARBUD Purwakarta. Peneliti berharap ada penelitian lebih lanjut dalam memperluas kemajuan dan media informasi dengan ide dan presentasi yang lebih mutakhir untuk masyarakat luas. sehingga setiap tahunnya akan meningkatkan potensi pengunjung sesuai target yang diharapkan oleh Dinas Olahraga, Pariwisata dan Kebudayaan Pemuda Kabupaten Purwakarta serta pemasaran Dinas Olahraga, Pariwisata dan Kebudayaan Pemuda Kabupaten Purwakarta. untuk selalu memanfaatkan pariwisata Kabupaten Purwakarta ini. video informasi pada acara-acara yang diadakan di wilayah Kabupaten. Purwakarta untuk dapat menarik lebih banyak kunjungan wisatawan.

\section{DAFTAR PUSTAKA}

[1] Maulani, G. Karina, M. T., dan Setiawan, I. (2019). Sistem Informasi UKKO Untuk Peningkatan Kinerja Kasus PegawaiStudi PT. PLN (persero) Tangerang. CCIT Journal, 12 (1), 1-12.

[2] Hidayat, Wahyu. Anita B. Wandanaya. Recha Fardiansyah. 2016. Perancangan Profil Video Sebagai Media Promosi dan Informasi di Sekolah Menengah Kejuruan Aviciena Rajeg Tangerang. Tangerang: STMIK Raharja. Jurnal CERITA. ISSN: 2461-1417. Vol. 2 No.1: 50.

[3] Ch. Ayo, Ferni Fera. 2016. Peran Promosi dalam Meningkatkan Kunjungan Wisatawan di Kabupaten Poso. Jurnal elektronik "Acta Diurna" Volume V.

[4] Sidik, Muhammad. Wahyu H dan Ulum, Ahmad Bahrul. 2019. Video Pinang TV Informasi di Kabupaten Pinang Kota Tangerang. Jurnal CICES Vol. 5 No. 2 
[5] Al Husain, Chandra. 2019. Perancangan Informasi Objek Wisata Curug Layung Melalui Media Video Dokumenter. Thesis. Program Studi Desain Komunikasi Visual. Universitas Komputer Indonesia. Bandung.

[6] Apriliani, Zohriyatun. Uswatun dan Andi. 2019. Pembuatan Video Profil dengan Efek Vintage Kampung Wisata Adat Sengkoah sebagai Media Informasi. Jurnal Teknologi Informasi dan Multimedia 1 (1). 57-65.

[7] Maulani, Giandari. Noviar Jalu Sasongko dan Ardi Mulyana. 2016. Pengembangan Media Promosi Pariwisata Kota Tangerang dalam Bentuk Video Digital pada Dinas Porparekraf. Universitas Raharja. Jurnal ICIT No.2 Vol. 2 ISSN: 2356 - 5195. 